\title{
Obesity and Cancer: yin/yan Effects of Nutrition
}

\author{
Iradj Sobhani ${ }^{*}, 1,2$, Jeand David Zeitoun ${ }^{1}$, Elise Chanteloup ${ }^{1}$, Antoine Charachon ${ }^{1}$, Michael Levy ${ }^{1}$ and \\ Jean Charles Delchier ${ }^{1}$
}

${ }^{I}$ Gastroenterology unit, Albert Chenevier-Henri Mondor Hospital-Assistance Publique-Hopitaux de Paris-AP-HP, Créteil 94010, France

${ }^{2}$ Université Paris 12-LIC EA4393

\begin{abstract}
For more than two decades, an increased interest in understanding relationship between obesity and cancer is observed in the medical literature. However, epidemiological data remain heterogeneous depending on cancer site, age, gender, type of tissue adipose (visceral, subcutaneous) and ethnicity: obesity is linked with a greater risk of colo-rectal cancer (CRC) for men of all ages and for premenopausal women. Mechanisms involved are not fully investigated: no specific genetic marker linking obesity and cancer is identified, and except for few metabolic markers, pathways in this field remain speculative. Effects of hormones are more investigated. Insulin is the best established biochemical mediator between obesity and CRC and insulin resistance is important in the pathogenesis of CRC. Leptin, a very well known hormone that regulates food intake and energy balance is reported as tumorigenic mediator to explain why polyps are over expressed in obese individuals, however it may influence also anti tumoral immune response. Regular exercise is identified to reduce the risk of developing CRC. We should consider exercise, obesity and anti tumor immune response when designing colon cancer screening protocols.
\end{abstract}

Keywords: Cancer, colon, obesity, leptin, immune response, adipopkine.

\section{INTRODUCTION}

Obesity is a complex, heterogeneous and multifactorial syndrome resulting from both genetic susceptibility and environmental factors [1]. In order to enhance understanding of this short review, we will focus mainly on colorectal cancers (CRC). Factors such as, hereditary disorders, familial adenomatous polyposis and non-polyposis syndrome and inflammatory bowel diseases, increase the risk for development of CRC [2]. The role of other factors like high fat and low fiber diet, low physical activity, overweight in increasing the risk of CRC is suspected but not fully established. Although energy restriction unequivocally reduces tumor development $[3,4]$ the contribution of nutritional factors to human deaths from CRC remains controversial [5, 6]. For instance, incidence of both CRC and obesity is increasing in all western countries and CRC is now the second most common cause of cancer mortality. In addition some of the risk factors for obesity, such as a high fat diet or decreased physical activity, have been shown in various studies to enhance risk for CRC as well, suggesting that there might be common biological events or undefined interactive events that result in a positive association between CRC and weight gain. Observations on such an association between changes in cancer incidence and environmental factors have allowed identifying microorganisms i.e. Helicobacter pylori and Human Papilloma Virus (HPV) as etiopathogenic factors in gastric and anal canal carcinomas. Such an association between CRC and nutritional factors is not yet fully

*Address correspondence to this author at the 51 Av Mal deLattre de Tassigny CRETEIL 94010, France; Tel: 33-1-49 814358 or 33-1-49 8123 62; Fax: 33-1- 498123 52; E mail: iradj.sobhani@hmn.aphp.fr established likely due to large variety of nutriments and various mechanisms involved. We will briefly review results from epidemiological data, summarize mechanisms involved and conclude on possible paradoxical effect of nutriment on cancer outcomes.

\section{EPIDEMIOLOGICAL DATA}

\section{Mortality due to the Cancer}

The relationships between excess body weight and mortality from all causes have been well-established in epidemiologic studies $[7,8]$. The association of overweight and obesity with non-cancer outcomes is generally stronger than the association with cancer. In all population studies, increases in the prevalence of obesity, hypertension, hyperlipidemia, and diabetes emerge earlier than increases in cancer outcomes. In addition, the relation of obesity to particular cancer sites has been more difficult to study because the incidence and mortality of specific types of cancer are less common than non-cancer outcomes. Thus, it seems unclear whether overall high incidence of mortality due to cancers result in accumulation of risks due to nutrition or should be considered as complication of obesity.

\section{High Prevalence of Cancer Occurrence in Obese and Overweight Individuals}

A significant link between obesity and cancers of the colon, postmenopausal female breast [1], endometrium, kidney [9], and esophagus has been suggested by several authors and accepted by IARC (International Agency for Research on Cancer). However, the report of IARC 
concluded that although an association between overweight and obesity and cancer at many sites is consistent with animal studies [10-13] there is no evidence on the cancerpreventive effect of avoidance of weight gain (IARC Handbooks of Cancer Prevention. Weight Control and Physical Activity. International Agency for Research on Cancer:Lyon.2007). Men of all ages and postmenopausal women, are at increased risk for CRC if they are obese [14]. Slattery ML et al. [15] have shown that in men, obesity and reduced physical activity result in an elevated risk of CRC, but in women this is, in part, offset by the reduced risk associated with the elevation of estrogen levels. Because a biologic mechanism that clearly links obesity to cancer has not been established [16] experimental designs to study whether cancers and obesity share same causes or they only result from endocrine and metabolic changes due to obesity are difficult to establish.

\section{No Definitive Evidence of Weight Reduction and Cancer Prognosis}

Interventional studies conducted in human are another way by which hypotheses can be verified. Because few individuals lose and maintain significant amounts of weight, it is extremely difficult to examine cancer incidence and cancer outcomes in large populations of weight losers. Studies performed in very obese individuals who had gastric bypass and those performed in patients who underwent cancer therapy give data on the incidence and outcomes of cancer depending on weight. Total cancer incidence was shown to be significantly lower in very obese patients who underwent gastric bypass compared to controls (hazard ratio $=0.76$; confidence interval 95\%, 0.65-0.89; $\mathrm{P}=0.0006)$. Significant reduction in total cancer mortality $(46 \%)$ in very obese patients who had gastric bypass was associated with decreased incidence particularly among subjects with advanced cancers. Authors suggested gastric bypass might reduce cancer risk, presumably related to weight loss [17]. However, such studies remain controversial since there is no evidence about how these obese patients have been selected for bypass surgery and whether the control group fits with the design. That the inverse association for mortality was not limited, in this study, to obesity related cancers but seen for all cancers, argued for bias in such approaches. Furthermore, in a comparative study of mucosal biomarkers in obese patients with BMI $>40 \mathrm{~kg} / \mathrm{m} 2$, Sainsbury et al. [18] did not observed any difference on colonic cell proliferation before and 6 months after gastric bypass. In spite of an association between excess body weight and elevated mucosal biomarkers of epithelial cell proliferation and crypt fission as compared to controls, authors concluded that risk for CRC may not be diminished with gastric bypass. Furthermore, an unexpected finding was that significant weight loss $(40 \%$ excess weight loss) 6 months after gastric bypass was still associated with increased crypt epithelial mitosis and luminal migration of the crypt proliferation zone, rather than a reduction toward values observed in normal weight individuals. Because persistent elevation of this biomarker of CRC risk would imply that obese patients, even after weight lose by gastric bypass remain at long-term increased risk of colorectal neoplasia, the main unresolved question is whether the hyperproliferative state is a transient phenomenon due to obesity or persists during long periods due to genetic characteristics and/or various other unsuspected environmental factors. In another interventional study [19] the influence of weight gain on outcome among patients who underwent curative surgery followed by adjuvant chemotherapy for stage III colon cancer has been prospectively evaluated and patients were monitored for cancer recurrence. Authors [19] did not observe any significant association between BMI and cancer recurrence and mortality. Similarly, weight gain after completion of adjuvant therapy did not negatively impact survival, although, the risk of recurrence (hazard ratios of $1.24 ; 95 \% \mathrm{CI}, 0.84$ to 1.83 ) for individuals with BMI $>35 \mathrm{~kg} / \mathrm{m} 2$ appeared slightly higher [19]. By contrast, increasing per cent body fat resulted in an increase in recurrence deaths (hazard ratio 1.33 per $10 \mathrm{~kg}$; $95 \% \mathrm{CI}=$ 1.04-1.71) in another study [20]. Possible mechanisms for these observations include altered carcinogen metabolism, decreased oxidative DNA damage, greater DNA repair capacity, and a reduction of IGF-I levels in calorie restricted animals [10].

\section{MECHANISMS INVOLVED}

Tumor progression is governed both by genetic events, intrinsic to cancer cells, and epigenetic and environmental factors. It is possible that the dominant and complex features of the dietary factors make it difficult to determine what factor is responsible for the relation between obesity and colon cancer.

\section{Gene Susceptibility}

Single gene mutations rarely account for obesity in human. It is likely that obesity is influenced by the interaction of multiple genes, each with modest effects, and further interactions with environmental factors such as energy availability, physical activity [16]. To identify obesity susceptibility genes two approaches have been adopted. First, candidate genes involved in the main metabolic pathways were investigated: food intake regulation by the central nervous system; modulation of insulin action and glucose metabolism in target tissues that may contribute to excess fat deposition and insulin resistance; and regulation of energy expenditure, lipid metabolism and oxidation, lipolysis [16]. Although a large series of association studies have been conducted relating genetic variation in candidate genes to obesity phenotypes [21], small, uncertain, or inconsistent effects could be documented. Obviously, for a small number of genes, including common polymorphisms in the peroxisome proliferator- activated receptor gamma (PPAR $\gamma$ ), the beta-adrenergic receptors ( $\beta$-AR2, $\beta$-AR3), leptin, leptin receptor $(\mathrm{ObR})$, and cytokines such as tumor necrosis factor alpha (TNF $\alpha$ ) and uncoupling protein genes (UCP-1, UCP-2, and UCP-3) findings were significant. The genome-wide scans in large numbers of obese individuals and their family members was an alternative approach. Such scans have been conducted in widely diverse ethnic populations [22] with no a priori assumptions about gene function; this method attempts to identify susceptibility genes simply by position. Up to now, about 70 human obesity loci on several chromosomes have been suggested; 18 loci have been replicated in at least two studies of different populations [21]. Positional cloning of genes in these regions is underway and some gene candidates for both cancer and 
obesity susceptibilities [23] may be available in future. Whether these genes are involved in the metabolism, cell cycle, energy pathways or transduction signals of cells requires still further investigation.

\section{PLACE OF HORMONES}

\section{a) Insulin and Insulin-Like Growth Factors (IGFs)}

Insulin appears the best established biochemical link between obesity and colon cancer; controlling hyperinsulinemic states, such as the metabolic syndrome and diabetes, may be a means of reducing risk of colon cancer. Energy restriction unequivocally reduces tumor development in animal models [11], but to study energy intake in relation to human cancer is complicated. In humans, variation in energy intake is determined by physical activity, body size, metabolic efficiency, and energy balance. Excess energy balance throughout life is the main critical factor for many cancers because positive associations for many cancers common in western countries are observed with obesity (surrogate of excess energy consumption), low physical activity (surrogate of energy expenditure), and taller height (surrogate of total lean body mass and high energy intake during development). This explains why intervention studies to reduce cancer risk remain difficult. At least part of the effect of excess energy is thought to be mediated through the insulin and IGF pathways [4]. Body weight has strong effects on circulating levels of these peptides and steroid hormones and their binding factors. Weight loss has been shown to reduce insulin resistance and circulating levels of insulin, glucose, and estradiol but the influence of weight loss on the levels of IGFs and associated binding proteins is less clear. The role of peptide $\mathrm{C}$, a fragment of pro insulin protein, characterized as marker of insulin resistance also remains controversial [14]. Specific effects vary somewhat by gender, by menopausal status in women and by type of fat tissue. Visceral associated fat (VAF), not subcutaneous or total body fat, is established as the particular location and source of the presumptive metabolic risk factors for colon cancer. Mice predisposed to develop visceral abdominal obesity developes hyperinsulinemia and preneoplastic colonic mucosal changes more often than mice without visceral abdominal obesity [14]. Insulin-like growth factors are mitogens that regulate energy-dependent growth processes, cell proliferation and inhibit apoptosis. Unfortunately, there is no empirical evidence with regard to the clinical manifestations of weight loss sustained over long periods of time regarding these peptides. And a recent study provides direct epidemiologic support for the hypothesis that long-term insulin therapy by itself increases the risk of CRC [24].

\section{b) Leptin and Leptin Receptor}

Leptin may also be responsible for the increased risk of colon cancer that obesity confers. Leptin, a 16-kilodalton product of the $o b$ gene, is mainly produced by fat tissue in human adults [25]. ObRb is the main isoform of the leptin receptor; it is expressed by colonocytes, and is preserved in human colonic adenomas and carcinomas [See review in refs 26, 27]. Obesity increases serum leptin levels [25]. Leptin was shown to increase the growth and proliferation of a colon cancer cell line, as evidenced by BrdU incorporation and c-fos expression and to work as a mitogen for intestinal epithelial cells via NFKB activation [27, 28]. In vitro, it decreases apoptotic cell death in a cancer cell line, induces invasion of collagen gel by cell lines derived from colonic adenomas [29, 30] and in vivo, it enhances the development of adenomatous polyps in genetically predisposed mice [31]. Various investigatory approaches have been undertaken. The role of hormones and their receptors in colon carcinogenesis was studied in obese animal models $(\mathrm{db} / \mathrm{db}$ obese mice, Zucker rat) due to hyperleptinemia by several authors [31, 32]. Although these models do not suitably reflect human obesity, authors could observe occurrence of premalignant lesions in the animal colon by delivering chemical i.e. azoxymethane (AOM) or N-methyl $\mathrm{N}$-nitrosurea, even under food-restricted conditions [31,32]. This strongly suggested "obesity-related carcinogenesis" would be a direct conesquence of chronic hyperleptinemia on the colon mucosa [33]. Whether it acts as a systemic hormone and/or as local mediator remains unclear. We failed to promote the growth of colon cancer xenografts in mice $[13,34]$ by administration of exogenous leptin. And relationship between colon cancer and serum leptin level appears controversial. Measuring leptin prior to the occurrence of colon cancer, men, but not women, with the highest blood levels of leptin have been shown to have over twice the colon cancer risk of those with the lowest levels [26]. Conversely, the serum concentration of leptin in CRC patients was found to be lower than in controls [35 \& personal data]. Tumor growth factors and cytokines produced by tumor cells can target hypothalamus. Lower level of leptin in CRC patients' serum can be explained by lower food intake and loss of fatty tissue and cachexia. This could be clearly shown for MIC-1, a key inducer of cancer related anorexia and weight loss that shares similarities with TGF $\beta$ [36]. Whether high leptin level in obese individuals enhances risk for colon cancer via direct effect on proliferation in the colonic mucosa, or by failure of leptin to activate NK cells or through cytokine production from colonocytes, remains unclear.

\section{c) Enigma of Leptin Effect}

Administration of leptin promotes experimental colitis by acting on colonocytes [37]. In vitro, leptin enhances cytokines and chemokine production from target cells by inducing the expression of NFKB [27]. Such pro inflammatory effect of leptin might support the idea that the innate immune system can promote tumor development through inflammation-dependent mechanisms [38]. Whether the pro inflammatory effect of leptin is beneficial or deleterious to tumor development remains an enigma. Besides the risk of elevated leptin acting as systemic and/or colon-limited mitogen, it may stimulate immune response [38].

Anti-tumoral immunity in CRC includes local control of metastatic invasion in CRC that has been recently shown to be linked to a continuous process from inflammatory cell to cytotoxic cell infiltration in tumors [39]. Also, tumors infiltrated by lymphocytes [40], particularly those with high level microsatellite instability (known as MSI-H or MSI), have a good prognosis, probably due to enhanced specific cytotoxic response [41]. Microsatellite instability is a genome-wide instability of repetitive DNA sequences observed at the nucleotide level; it is caused by the inactivation or 
loss of expression of mismatch repair (MMR) genes, either as a result of mutations or of epigenetic silencing [40]. Slattery ML et al. [15] have shown that risk for colon cancer in women (but not in men) was confined to MSI tumors. We have shown that immune response to colon cancer was dependent on both levels of microsatellite insta-bility and numbers of leptin receptors expressed by colon tumor cells [34, 42, 43]. In those colon tumors with high level MSI, leptin receptor [42], and mediators of cytotoxic T cells [41] were overerexpressed in response to leptin. These results suggest involvement of leptin in immune anti tumor response and sustained occurrence of chemical-induced premalignant tumors in mice carrying the leptin-receptor $\mathrm{db} / \mathrm{db}$ mutation compared to wild type animals [31] and increased susceptibility to spontaneous colonic tumors in mice deficient in one or more components of the immune system [44]. Direct action of nutrient on the immune system [45], raises the question of adequate intakes of "good" (immune stimulant) nutriments, and "bad" (high energetic) nutrmients.

\section{CONCLUSION}

Nutrition stimulates the immune system and is necessary for energy expenditure. Several hormones regulate food uptake and energy balance. These hormones are very often involved in the regulation of immune responses. Obesity is strongly linked with changes in levels and/or regulatory pathways of these hormones. Overexpression of some of these hormones may favor occurrence of cancer. Whether, they imitate cancer phenomena or promote tumors is not established. We should now study putative effects of environmental factors including nutrition and exercises on both tumor occurrence and anti cancer immune protective responses.

\section{REFERENCES}

[1] Ogden CL, Yanovski SZ, Carroll MD, Flegal KM. The epidemiology of obesity. Gastroenterology 2007; 132(6): 2087102.

[2] Danaei G, Vander HS, Lopez AD, Murray CJ, Ezzati M. Causes of cancer in the world: comparative risk assessment of nine behavioural and environmental risk factors. Lancet 2005; 366(9499):1784-93.

[3] Lin J, Zhang SM, Cook NR, et al. Dietary intakes of fruit, vegetables, and fiber, and risk of colorectal cancer in a prospective cohort of women (United States). Cancer Causes Control 2005; 16(3):225-33

[4] McCullough ML, Giovannucci EL. Diet and cancer prevention. Oncogene 2004; 23(38): 6349-64.

[5] Kim EHJ, Willett WC, Colditz GA, et al. Dietary Fat and Risk of Postmenopausal Breast Cancer in a 20-year Follow-up. Am J Epidemiol 2006; 164(10): 990-7.

[6] Murphy TK, Calle EE, Rodriguez C, Kahn HS, Thun MJ. Body mass index and colon cancer mortality in a large prospective study. Am J Epidemiol 2000; 152(9): 847-54.

[7] Calle EE, Thun MJ, Petrelli JM, Rodriguez C, Heath CW, Jr. Body-mass index and mortality in a prospective cohort of U.S. adults. N Engl J Med 1999; 341(15): 1097-105.

[8] Rapp K, Schroeder J, Klenk J, et al. Obesity and incidence of cancer: a large cohort study of over 145,000 adults in Austria. Br J Cancer 2005; 93(9): 1062-7.

[9] Pyridopoulos TN, Petridou ET, Skalkidou A, Dessypris N, Chrousos GP, Mantzoros CS. Low adiponectin levels are associated with renal cell carcinoma: a case-control study. Int J Cancer 2007; 120(7): 1573-8.
[10] Dunn SE, Kari FW, French J, et al. Dietary restriction reduces insulin-like growth factor I levels, which modulates apoptosis, cell proliferation, and tumor progression in $\mathrm{p} 53$-deficient mice. Cancer Res 1997; 57(21): 4667-72.

[11] Hursting SD. Experimental models of gene-environment interaction for cancer chemoprevention studies. Curr Opin Oncol 1997; 9(5): 487-91.

[12] Hursting SD, Perkins SN, Brown CC, Haines DC, Phang JM. Calorie restriction induces a p53-independent delay of spontaneous carcinogenesis in p53-deficient and wild-type mice. Cancer Res 1997; 57(14): 2843-6.

[13] Aparicio T, Kotelevets L, Tsocas A, et al. Leptin stimulates the proliferation of human colon cancer cells in vitro but does not promote the growth of colon cancer xenografts in nude mice or intestinal tumorigenesis in $\mathrm{Apc}(\mathrm{Min} /+)$ mice. Gut 2005; 54(8): 1136-45.

[14] Frezza EE, Wachtel MS, Chiriva-Internati M. Influence of obesity on the risk of developing colon cancer. Gut 2006; 55(2): 285-91.

[15] Slattery ML, Potter JD, Curtin K, et al. Estrogens reduce and withdrawal of estrogens increase risk of microsatellite instabilitypositive colon cancer. Cancer Res 2001; 61(1): 126-30.

[16] Calle EE, Thun MJ. Obesity and cancer. Oncogene 2004; 23(38): 6365-78.

[17] Adams TD, Stroup AM, Gress RE, et al. Cancer incidence and mortality after gastric bypass surgery. Obesity (Silver Spring) 2009; 17(4): 796-802.

[18] Sainsbury A, Goodlad RA, Perry SL, Pollard SG, Robins GG, Hull MA. Increased colorectal epithelial cell proliferation and crypt fission associated with obesity and roux-en-Y gastric bypass. Cancer Epidemiol Biomarkers Prev 2008; 17(6): 1401-10.

[19] Meyerhardt JA, Niedzwiecki D, Hollis D, et al. Impact of body mass index and weight change after treatment on cancer recurrence and survival in patients with stage III colon cancer: findings from Cancer and Leukemia Group B 89803. J Clin Oncol 2008; 26(25): 4109-15.

[20] Haydon AM, MacInnis RJ, English DR, Giles GG. Effect of physical activity and body size on survival after diagnosis with colorectal cancer. Gut 2006; 55(1): 62-7.

[21] Chagnon YC, Rankinen T, Snyder EE, Weisnagel SJ, Perusse L, Bouchard C. The human obesity gene map: the 2002 update. Obes Res 2003; 11(3): 313-67.

[22] Clement K, Boutin P, Froguel P. Genetics of obesity. Am J Pharmacogenomics 2002; 2(3): 177-87.

[23] Scott BB, Zaratin PF, Clarke GD, et al. C20orf9-003 (ACI-1), a gene localized on chromosome 20q13.12 encoding for a $49 \mathrm{kD}$ cytoplasmic protein with a putative nucleotide binding site. DNA Seq 2004; 15(1): 1-8.

[24] Yang YX, Hennessy S, Lewis JD. Insulin therapy and colorectal cancer risk among type 2 diabetes mellitus patients. Gastroenterology 2004; 127(4): 1044-50.

[25] Friedman JM, Halaas JL. Leptin and the regulation of body weight in mammals. Nature 1998; 395(6704): 763-70.

[26] Stattin P, Lukanova A, Biessy C, et al. Obesity and colon cancer: does leptin provide a link? Int J Cancer 2004; 109(1): 149-52.

[27] Matarese G, Moschos S, Mantzoros CS. Leptin in immunology. J Immunol 2005; 174(6): 3137-42.

[28] Rouet-Benzineb P, Aparicio T, Guilmeau S, et al. Leptin counteracts sodium butyrate-induced apoptosis in human colon cancer HT-29 cells via NF-kappaB signaling. J Biol Chem 2004; 279(16): 16495-502.

[29] Hirose Y, Hata K, Kuno T, et al. Enhancement of development of azoxymethane-induced colonic premalignant lesions in C57BL/KsJ-db/db mice. Carcinogenesis 2004; 25(5): 821-5.

[30] Attoub S, Noe V, Pirola L, et al. Leptin promotes invasiveness of kidney and colonic epithelial cells via phosphoinositide 3-kinase-, rho-, and rac-dependent signaling pathways. FASEB J 2000; 14(14): 2329-38.

[31] Hirose Y, Hata K, Kuno T, et al. Enhancement of development of azoxymethane-induced colonic premalignant lesions in C57BL/KsJ-db/db mice. Carcinogenesis 2004; 25(5): 821-5.

[32] Lee WM, Lu S, Medline A, Archer MC. Susceptibility of lean and obese Zucker rats to tumorigenesis induced by N-methyl-Nnitrosourea. Cancer Lett 2001; 162(2): 155-60.

[33] Hardwick JC, van den Brink GR, Offerhaus GJ, Van Deventer SJ, Peppelenbosch MP. Leptin is a growth factor for colonic epithelial cells. Gastroenterology 2001; 121(1): 79-90. 
[34] Abolhassani M, Aloulou N, Chaumette MT, et al. Leptin receptorrelated immune response in colorectal tumors: the role of colonocytes and interleukin-8. Cancer Res 2008; 68(22): 9423-32.

[35] Kumor A, Daniel P, Pietruczuk M, Malecka-Panas E. Serum leptin, adiponectin, and resistin concentration in colorectal adenoma and carcinoma (CC) patients. Int J Colorectal Dis 2009; 24(3): 275-81.

[36] Johnen H, Lin S, Kuffner T, et al. Tumor-induced anorexia and weight loss are mediated by the TGF-beta superfamily cytokine MIC-1. Nat Med 2007; 13(11): 1333-40.

[37] Sitaraman S, Liu X, Charrier L, et al. Colonic leptin: source of a novel proinflammatory cytokine involved in IBD. FASEB J 2004; 18(6): 696-8.

[38] Coussens LM, Werb Z. Inflammation and cancer. Nature 2002; 420(6917): 860-7.

[39] Pages F, Berger A, Camus M, et al. Effector memory T cells, early metastasis, and survival in colorectal cancer. N Engl J Med 2005; 353(25): 2654-66.

[40] Guidoboni M, Gafa R, Viel A, et al. Microsatellite instability and high content of activated cytotoxic lymphocytes identify colon cancer patients with a favorable prognosis. Am J Pathol 2001; 159(1): 297-304

[41] Le GS, Bastuji-Garin S, Aloulou N, et al. High prevalence of Foxp3 and IL17 in MMR-proficient colorectal carcinomas. Gut 2008; 57(6): 772-9.

[42] Aloulou N, Bastuji-Garin S, Le GS, et al. Involvement of the leptin receptor in the immune response in intestinal cancer. Cancer Res. 2008; 68(22): 9413-22.

[43] Le Gouvello S, Bastuji-Garin S, Aloulou N, et al. High prevalence of Foxp3 and IL-17 in MMR-proficient colorectal carcinomas. Gut 2007.

[44] Dunn GP, Bruce AT, Ikeda H, Old LJ, Schreiber RD. Cancer immunoediting: from immunosurveillance to tumor escape. Nat Immunol 2002; 3(11): 991-8.

[45] Moskovitz DN, Kim YI. Does perioperative immunonutrition reduce postoperative complications in patients with gastrointestinal cancer undergoing operations? Nutr Rev 2004; 62(11): 443-7.

(C) Sobhani et al.; Licensee Bentham Open.

This is an open access article licensed under the terms of the Creative Commons Attribution Non-Commercial License (http://creativecommons.org/licenses/by$\mathrm{nc} / 3.0 /$ ), which permits unrestricted, non-commercial use, distribution and reproduction in any medium, provided the work is properly cited. 